\title{
GA Analysis of Switchability of Ferrite Rectangular Patch Antenna
}

\author{
${ }^{1}$ Naveen Kumar Saxena, ${ }^{1}$ Raj Kumar Verma, ${ }^{1}$ P.K.S. Pourush, \\ ${ }^{2}$ Nitendar Kumar \\ ${ }^{1}$ Microwave Lab, Department of Physics, Agra College Agra, PIN 282002 (U.P), India. \\ ${ }^{2}$ Solid State Physics Laboratory, Timarpur, Delhi, India.
}

\begin{abstract}
The application of Genetic Algorithm (GA) to analyze / optimize the switching behavior of magnetically biased switchable microstrip antenna, fabricated on ferrite substrate, is reported. In this work, GA has been applied to optimize extraordinary wave propagation constant $\left(K_{e}\right)$ which is mainly responsible for the switchability of antenna. The wave propagation constant becomes zero or negative under proper magnetic biasing which resist the antenna as radiator without a mechanical maneuvering. The fitness functions for the GA program have been developed using mathematical formulation based on nonreciprocal approach of ferrite substrate under external magnetic field. The computed results are in good agreement with the results obtained experimentally and trained artificial neural network analysis. In this ANN training Radial Basis Function $(R B F)$ networks is used. All programming related to genetic algorithm and ANN analysis performed by MatLab 7.1.
\end{abstract}

Keywords: Microstrip rectangular patch antenna, genetic algorithm, fitness function, ferrite substrate, magnetic biasing, ANN analysis training, etc.

\section{Introduction}

In recent years there are lots of works exercised in the microwave field with the help of artificial intelligence tool. The substituted polycrystalline ferrite with DC magnetic biasing is offers number of novel magnetic and electrical characteristics including switchable and polarized radiations from a microstrip antenna. In such a case of antenna radiation, most of the power will be converted into mechanical waves and little radiates into air. Under such condition the antenna become switch off, in the sense of effectively absence as radiator. It is well known that the search technique genetic algorithm is a parallel, robust and probabilistic which can easily implemented without gradient calculation, compare with the conventional gradient base search procedure. Most important of all, the GA proposed also provides a mechanism for global search that is not easily trapped in local optima. The GA proposed here an adaptive mutation rate strategy. Although some work [1-6, 32-33] have been performed for microstrip antenna with GA approach for the patch antennas without magnetic biasing but analysis of switchability of antenna printed on ferrite substrate under magnetic biasing for rectangular patch antenna is new one. Present analysis also incorporate the dispersion effects due to magnetic field biasing in the form of effective propagation constant $(\mathrm{Ke})$ which is not discussed in the referenced articles. Some similar referenced works [7-11] also have done mathematically or by conventional methods for optimization but this technique is rather precise, accurate and sensitive to optimize parameters of patch antenna as well as other type of antenna also. There are many optimization techniques frequently using for the same work. GA's were introduced by Holland [24] and were applied to many practical problems by Goldberg [25, 26]. It is well known that search technique, the genetic algorithm is a parallel, robust and probabilistic search technique that is simply and easily implemented without gradient calculation, compare with the conventional gradient base search procedure. Most important of all, the GA proposed also provides a mechanism for global search that is not easily trapped in local optima. The GA proposed here an adaptive mutation rate strategy.

\section{Structure \& Theory of Antenna:}

Structure of microstrip rectangular patch antenna is depicted in fig. 1. Here ' $\mathrm{L}$ ' and ' $\mathrm{W}$ ' are the length and width of microstrip patch respectively. Patch is modeled on LiTiZn ferrite substrate of thickness ' $h$ '. The dielectric constant and saturation magnetization $\left(4 \pi M_{s}\right)$ of substrate is 15 and 2200 Gauss respectively.

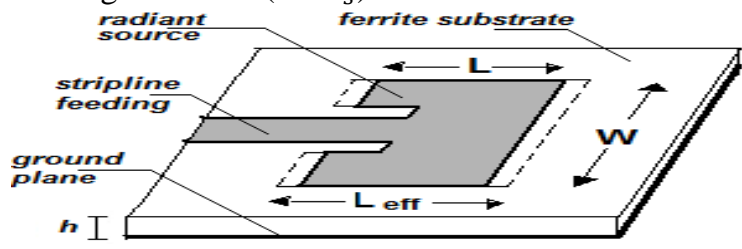

Figure 1: Schematic Diagram of Microstrip Rectangular Patch Antenna 
It has been established that, for a biased ferrite slab, a normal incident plane wave may excite two types of waves (ordinary and extraordinary wave). In the case of normal incident magnetic field biasing ordinary wave is same as the plane wave in the dielectric slab. On the other hand, the extraordinary wave is a TE mode polarized parallel to the biasing direction with its phase propagation constant $\mathrm{Ke}$ [12-15].

$$
\begin{aligned}
& K_{e}=\frac{w}{c} \sqrt{\epsilon_{\text {eff }} \times \mu_{\text {eff }}} \\
& K_{d}=\frac{w}{c} \sqrt{\epsilon_{\text {eff }}} \\
& \mu_{\text {eff }}=\frac{\mu^{2}-k^{2}}{\mu} \\
& \mu=1+\frac{w_{o} w_{m}}{w_{o}^{2}-w^{2}} \\
& k=\frac{w w_{m}}{w_{o}^{2}-w^{2}}
\end{aligned}
$$

with

$$
w_{o}=\gamma H_{o} \text { and } w_{m}=\gamma 4 \pi M_{s}
$$

Where $H_{o}$ is the bias field, $4 \pi M_{S}$ is the saturation magnetization, $\gamma$ is the gyromagnetic ratio as $\gamma=$ $2.8 \mathrm{MHz} . / \mathrm{Oe}$.

\section{Application of Genetic Algorithm to the Microstrip Antenna and Computed Results:}

All the basic parameters, that is, ordinary wave propagation constant (Kd), Applied magnetic frequency (wo), Internal magnetic frequency (wm) and cutoff frequency (w) are coded into 5 bit scaled binary coding. Hence the total length of the chromosome was 20 bits. The Roulette wheel selection was used for GA population. The genetic algorithm was run for 50 generations.

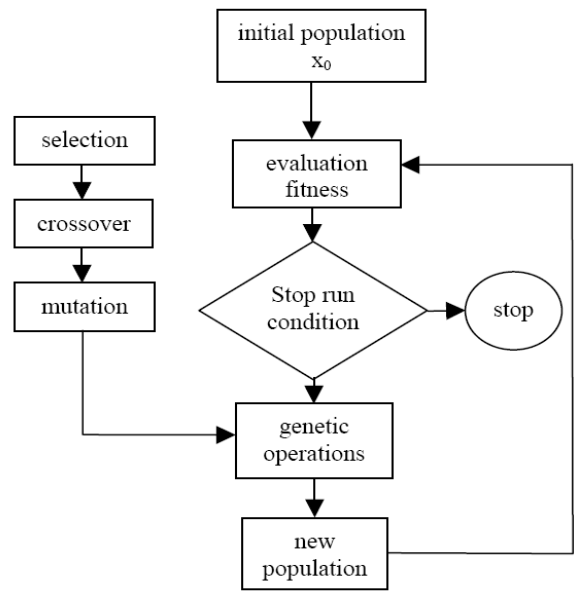

Figure 2: Flow Chart of Genetic Algorithm

The probability of crossover was varied from 0.7 to 0.85 and the probability of mutation was varied from 0.001 to 0.002 . The fitness function expression of antenna used for optimization is:

$$
\left(\frac{K_{e}}{K_{d}}\right)^{2}=\frac{\left(w_{o}+w_{m}\right)^{2}-w^{2}}{w_{o}\left(w_{o}+w_{m}\right)-w^{2}}
$$

The GA consists of five components. These are the random number generator, a fitness evaluation unit and genetic operators for reproduction, crossover and mutation operations. The flow chart, for optimization of microstrip antenna, using GA, is shown in fig. 2. 


\section{Results and Calculations:}

Obtained results (table 1 and fig. 3) show the variation of best, mean and expected values of extraordinary wave propagation constant (Ke) of antenna.

Table 1: Generation of fittest value through genetic algorithm

\begin{tabular}{|c|cccc|c|}
\hline Pop. No. & $\mathbf{K}_{\mathbf{d}}$ & $\mathbf{w}_{\mathbf{0}}$ & $\mathbf{W}_{\mathbf{m}}$ & $\mathbf{W}$ & $\mathbf{K}_{\mathbf{e}}$ \\
\hline $\mathbf{1}$ & 12.0299 & 5.1611 & 7.0000 & 7.1377 & 0.5013 \\
\hline $\mathbf{2}$ & 12.0299 & 5.1611 & 7.0000 & 7.1377 & 0.0513 \\
\hline $\mathbf{4}$ & 12.0299 & 5.1611 & 7.0000 & 7.1377 & 0.5130 \\
\hline $\mathbf{5}$ & 12.0299 & 5.1611 & 7.0313 & 7.1377 & 0.3513 \\
\hline $\mathbf{6}$ & 12.0299 & 5.1611 & 7.0000 & 7.1377 & 0.3513 \\
\hline $\mathbf{7}$ & 12.0299 & 5.1611 & 7.0000 & 7.1377 & 0.0883 \\
\hline $\mathbf{8}$ & 12.0299 & 5.1611 & 7.0000 & 7.1377 & 0.2774 \\
\hline $\mathbf{9}$ & 12.0299 & 5.1611 & 7.0000 & 7.1377 & 0.1142 \\
\hline $\mathbf{1 0}$ & 12.0299 & 5.1611 & 7.0000 & 7.1377 & 0.3513 \\
\hline $\mathbf{1 1}$ & 12.0299 & 5.1611 & 7.0000 & 7.1377 & 0.3513 \\
\hline $\mathbf{1 2}$ & 12.2799 & 5.1611 & 7.0000 & 7.1377 & 0.2513 \\
\hline $\mathbf{1 4}$ & 12.0299 & 5.1611 & 7.0000 & 7.1377 & 0.3513 \\
\hline $\mathbf{1 5}$ & 12.0143 & 5.1611 & 7.0000 & 7.1377 & 0.3513 \\
\hline $\mathbf{1 6}$ & 12.0299 & 5.1611 & 7.0000 & 7.1377 & 0.3513 \\
\hline $\mathbf{1 7}$ & 12.0299 & 5.1611 & 7.0000 & 7.1377 & 0.1118 \\
\hline $\mathbf{1 8}$ & 12.0299 & 5.1611 & 7.0000 & 7.1377 & 0.3513 \\
\hline $\mathbf{1 9}$ & 12.0299 & 5.1611 & 7.0000 & 7.1220 & 0.2644 \\
\hline $\mathbf{2 0}$ & 12.2799 & 5.1611 & 7.0000 & 7.0908 & 0.2647 \\
\hline
\end{tabular}

Best: 0.3811 Mean: 0.3812
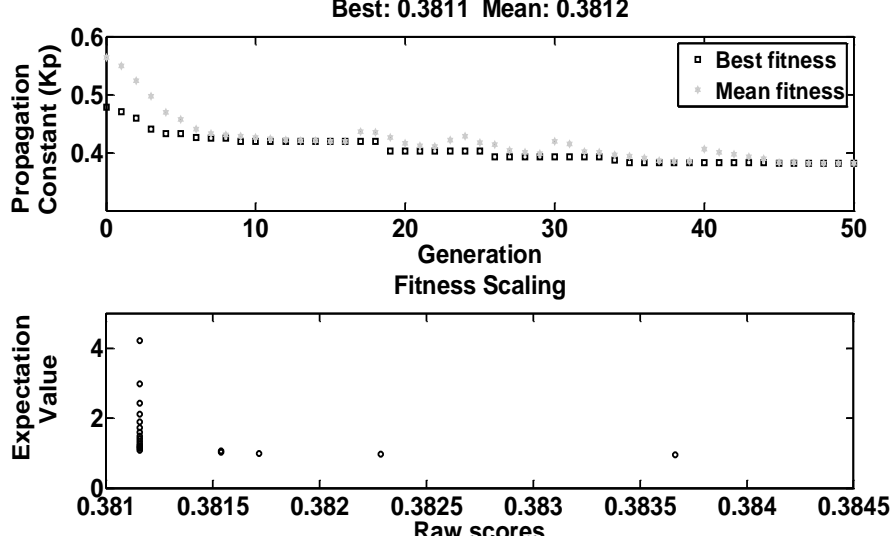

Fig. 3: Variation of Best, Mean and Expected value of Cutoff Frequency of Biased Rectangular Patch Antenna

The artificial neural network training program (based on RBF) also runs to optimize the cutoff frequency. In this RBF network, the spread value was chosen as 0.01 , which gives the best accuracy. RBF is tested with 100 samples frequencies but trained only for particular 20 samples frequencies. For ANN calculation by RBF, differ-differ values arrange as target from literature and experimental data [6-9].

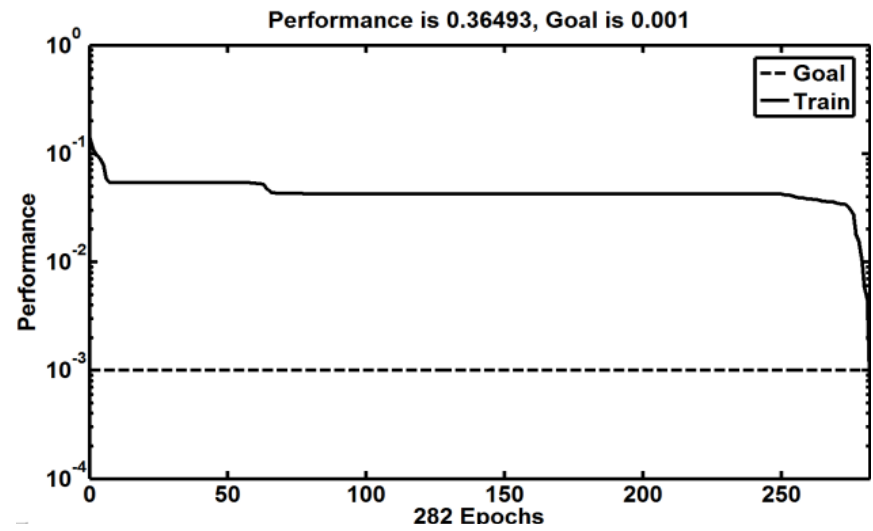

Fig. 4 Training Response of Artificial Neural Network program of Optimization of Cutoff Frequency at 253 Epochs 
Calculated values of extra ordinary propagation constant of microstrip rectangular patch antenna with GA program are compared with neural analysis results (fig. 4 and table 2) and experimental dispersion curve (fig. 5) which are in good agreement. This curve is plotted at 1550 Oe for LiTiZn-ferrite slab at SSPL Timarpur Delhi, on which microstrip patch antenna has been designed [6-16].

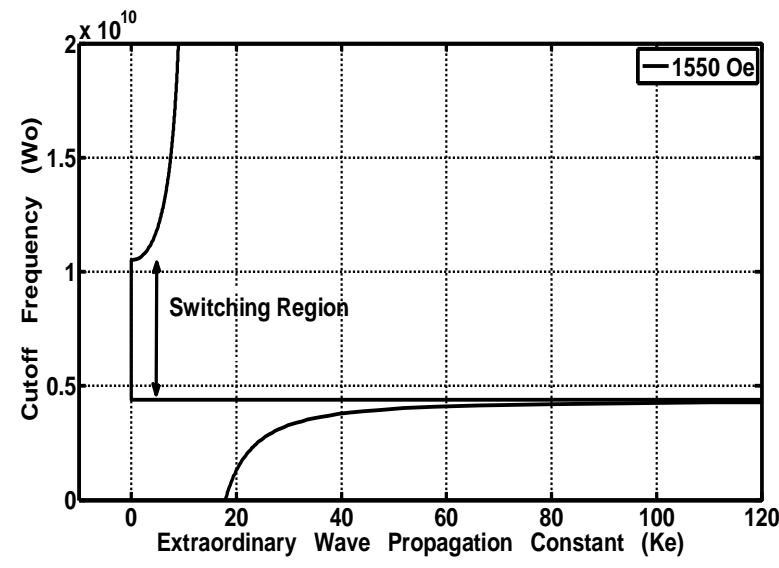

Fig.5. Dispersion curve (w Vs. Ke) for plane wave propagation perpendicular to biasing field

Table 2: Results of the ANN Analysis and comparison with target

\begin{tabular}{|c|c|c|c|c|c|}
\hline $\begin{array}{c}\text { Ordinary } \\
\text { Wave prop. } \\
\text { constant } K_{d}\end{array}$ & $\begin{array}{c}\text { Applied } \\
\text { mag. freq. } \\
w_{O}(\mathrm{GHz})\end{array}$ & $\begin{array}{c}\text { Internal } \\
\text { mag. freq. } \\
w_{m}(\mathrm{GHz})\end{array}$ & $\begin{array}{c}\text { Cutoff freq. } \\
w-\mathrm{RBF} \\
(\mathrm{GHz})\end{array}$ & $\begin{array}{c}\text { Extraordinary wave } \\
\text { propag. Constant } \\
K_{e} \text { - target } \\
\end{array}$ & $\begin{array}{c}\text { Extraor-dinary wave } \\
\text { propag. Constant } \\
K_{e}-\mathrm{RBF}\end{array}$ \\
\hline 12.50 & 4.2000 & 6.1575 & 6.4277 & 0.3221 & 0.3683 \\
\hline 12.50 & 4.3400 & 5.9816 & 6.2392 & 0.9976 & 0.9901 \\
\hline 11.50 & 4.3680 & 6.0168 & 6.1763 & 0.9991 & 0.9671 \\
\hline 12.00 & 4.2896 & 6.0520 & 6.5973 & 0.5475 & 0.5247 \\
\hline 12.50 & 4.2560 & 5.8408 & 5.2150 & 0.1858 & 0.1869 \\
\hline 11.50 & 4.2280 & 6.2279 & 5.7993 & 0.4002 & 0.4133 \\
\hline 11.00 & 4.3120 & 6.3335 & 5.8622 & 0.4010 & 0.3462 \\
\hline 10.55 & 4.3120 & 6.2631 & 6.4277 & 0.3319 & 0.3362 \\
\hline 10.00 & 4.2616 & 6.2983 & 6.7418 & 0.3187 & 0.3168 \\
\hline 12.50 & 4.2308 & 5.8408 & 5.8308 & 0.6718 & 0.6711 \\
\hline 12.50 & 4.2336 & 5.9464 & 5.7993 & 0.9566 & 0.9441 \\
\hline 11.50 & 4.2364 & 6.1223 & 6.9303 & 0.3187 & 0.3222 \\
\hline 12.50 & 4.2700 & 6.0871 & 7.0371 & 0.3190 & 0.3276 \\
\hline 12.50 & 4.3848 & 6.3335 & 4.9825 & 0.5751 & 0.5780 \\
\hline 11.55 & 4.3540 & 6.1927 & 4.5741 & 0.9944 & 0.9892 \\
\hline 11.55 & 4.6068 & 6.3335 & 6.2831 & 0.7059 & 0.6977 \\
\hline 12.55 & 4.0700 & 6.0871 & 7.0571 & 0.3193 & 0.3683 \\
\hline 11.55 & 4.3048 & 6.3035 & 4.0825 & 0.5711 & 0.9901 \\
\hline 10.55 & 4.3500 & 6.0927 & 6.5741 & 0.9949 & 0.9671 \\
\hline 10.00 & 4.0068 & 6.3005 & 6.2031 & 0.7058 & 0.5247 \\
\hline
\end{tabular}

Table 3: Results through various techniques and experimental works.

\begin{tabular}{|l|c|c|c|c|c|}
\hline \multicolumn{1}{|c|}{ Techniques } & wo $(\mathrm{GHz})$ & wm $(\mathrm{GHz})$ & w $(\mathrm{GHz})$ & Kd & Ke \\
\hline Genetic Algorithm & 5.1999 & 7.0135 & 7.1265 & 7.0380 & 0.3019 \\
\hline Neural Analysis & 4.6368 & 6.3335 & 6.2912 & 12.700 & 0.3333 \\
\hline Experimental Graph & 4.2000 & 6.1600 & 5.7180 & 8.4939 & 0.2853 \\
\hline
\end{tabular}

\section{Conclusions}

Rather than finding a single solution, optimization implies finding many solutions then selecting the best one. Optimization is an inherently slow, difficult procedure, but it is extremely useful when well done. The difficult problem of optimizing an electromagnetic design has only recently received extensive attention. The computed graphs and results show a good performance in comparison (table 3) of ANN analysis and also have good agreement with the results obtained experimentally. Some other types of problems related to the optimization of biased microstrip antennas can also be sort out by the genetic algorithm for the better performance.

\section{Acknowledgement}

The authors are grateful to Dr. R Muralidharan, Director "Solid State Physics Laboratory, Timarpur, Delhi" for providing necessary facilities, encouragement and motivation to carry out this work. 


\section{References}

[1] Haupt R. L., (1995), “An Introduction to Genetic Algorithms for Electromagnetics”, IEEE Trans. Antennas Propagation Magazine, Vol. 37, pp. 7-15.

[2] Chattoraj N. and Roy J. S., (2006), "The Optimization of Gain of Patch Antennas Using Genetic Algorithm”, ACTA Tech CSAV Journal.

[3] Villegas F. J., Cwik T., Rahamat-Samii Y. and Manteghi M., (2004), "A Parallel Electromagnetic Genetic- Algorithm Optimization (EGO) Application for Patch Antenna Design", IEEE Trans. Antennas Propagation, Vol. 52, pp. 2424-2435.

[4] Wyant A. M., (2007), "Genetic Algorithm Optimization Applied to Planar and Wire Antennas", Thesis submitted to Rochester Institute of Technology, Rochester, New York.

[5] Akdagli A. and Guney K., (2000), "Effective Patch Radius Expression Obtained Using a Genetic Algorithm for the Resonant Frequency of Electrically Thin and Thick Circular Microstrip Antennas", IEE Proc. Microwave and Antennas, Propagation, Vol. 147, No.2, pp.-156-159.

[6] Chattoraj N. and Roy J. S., (2005), "Investigations on Microstrip Antennas Covered with a Dielectric Layer using Genetic Algorithm", Presented in URSI Conference, New Delhi, October.

[7] Saxena N.K., Khan A., Pourush P.K.S and Kumar N., (2009), “ANN Analysis Optimization of Dielectric Constant \& Side Length of Microstrip Triangular Patch Antenna”, International Journal of Computational Intelligence Research, Vol. 6(1), pp. 165-170, 2010.

[8] Saxena N.K., Khan A., Pourush P.K.S and Nitendar Kumar, "Neural Network Analysis of Switchability of Microstrip Rectangular Patch Antenna Printed on Ferrite Material", International Journal of RF and Microwave Computer-Aided Engineering, Vol. 20(1), pp. 1-5, 2009 .

[9] Chiu Tang-Jung, Kuo Yi-Ting, Chao Hsueh-Yung (Robert), and Li Yi-Ming, (2007), “Optimization of Physics-Based Equivalent Circuits for Microstrip Patch Antennas”, IEEE Trans. Antennas Propagation, Vol.AP-40, pp.-5785-5788.

[10] Jackson D. R. and Alexopoulos N. G., (1991), "Simple approximation formulas for input resistance, bandwidth, and efficiency of a resonant rectangular patch," IEEE Trans. Antennas Propagation, Vol. 39, no. 3, pp. 407-410.

[11] Li' Zhifang and Volakis John L., (1999), "Optimization of Patch Antennas on Ferrite Substrate Using the Finite Element Methods", IEEE Trans. Antennas Propagation, Vol. 41, pp.-1026-1029.

[12] Pozar D.M., (1992), "Radiation and Scattering Characteristics of Microstrip Antennas on Normally Biased Ferrite Substrates", IEEE Trans. Antennas Propagation, Vol.AP-40, pp.1084-1092.

[13] Dixit L. and Pourush P. K. S., (2000), "Radiation Characteristics of Switchable Ferrite Microstrip Array Antenna", IEE Proc. Microwave and Antennas, Propagation, Vol. 147, No.2, pp. - 151-155.

[14] Stern R. A., Babbit R. W. and Borowick J., (1987), “A mm-Wave Homogeneous Ferrite Scan Antenna”, Microwave J., pp. 101108.

[15] Henderson A., James J. R. and Frey D., (1988), “Magnetic Microstrip Antenna with Pattern Control”, Electron. Letters, Vol. 24, pp. 45-47.

[16] Pozar D. M. and Sanchez V., (1988), "Magnetic Tuning of a Microstrip Antenna on Ferrite Substrate”, Electron. Letters, Vol. 24, pp. 729-731.

[17] Pozar D. M., (1989), "Radar Cross-Section of Microstrip Antenna on Normally Biased Ferrite Substrates", Electron. Letters, Vol. 25, pp. 1079-1080.

[18] Roy J.S., Vaudon P., Reineix A., Jecko F. and Jecko B., (1992), "Circularly Polarized Far Fields of an Axially Magnetized Circular Ferrite Microstrip Antenna", Microwave and Optical Technology Letts. Vol. 5, No.5, pp. 228-230.

[19] Roy J.S., Vaudon P., Reineix A., Jecko F. and Jecko B., (1992), "Axially Magnetized Circular Ferrite Microstrip Antenna”, Proc. IEEE Antennas Propagation and URSI joint Int. Symposium, Chicago, USA, Vol. 4, pp. 2212-2215.

[20] Das N., Chowdhury S. K. and Chatterjee J. S., (1983), "Circular Microstrip Antenna on a Ferrimagnetic Substrate", IEEE Trans. Antennas Propagation, Vol.AP-31, pp. 188-190.

[21] Roy J.S., Vaudon P., Jecko F. and Jecko B., (1992), "Magnetized Circular Ferrite Microstrip Antenna”, Proc. of Int. Symposium on Antennas Propagat., Proc. ISAP '92, Sapparo Japan, pp 765-768.

[22] Roy J.S. and Chattoraj N., (2002), "Magnetically Biased Ferrite Micrsotrip Antenna”, Proc. APSYM, Cochin, India, pp. 288-291.

[23] Green J. J. and Sandy F., (1974), "Microwave Characterization of Partially Magnetized Ferrites", IEEE Trans. Microwave Theory Tech., Vol. MTT-22, pp. 641-645.

[24] León G., Boix R. R., and Medina F., (2004), "Tunability and Bandwidth of Microstrip Filters Fabricated on Magnetized Ferrites", IEEE Microwave And Wireless Components Letters, Vol. 14, No. 4.

[25] León G., Boix R. R., and Medina F., (2002), "Full-wave analysis of a wide class of microstrip resonators fabricated on magnetized ferrites with arbitrarily oriented bias magnetic field," IEEE Trans. Microwave Theory Tech., vol. 50, pp. 1510-1519.

[26] How H. and Fang T. M., (1994), "Drop-On Circulator Design at X and Ka Bands", IEEE Transactions on Magnetics. Vol. 30, No. 6.

[27] J. H. Holland, (1975), Adaptation in Natural and Artificial Systems, Univ. Michigan Press, Ann Arbor.

[28] D. E. Goldberg, (1989), Genetic Algorithms in Search, Optimization, and Machine Learning, Addison-Wesley, New York.

[29] Goldberg D. E., (1989), Genetic Algorithms, Addison-Wesley.

[30] Sodha M.S. and Srivastav N.C., (1981), "Microwave Propagation in Ferrimagnetics", Plenum Press, New York.

[31] Garg R., Bhartia P., Bahl I. and Ittipiboon A., (2001), Microstrip Antenna Design Handbook, Artech House.

[32] Mohd. A., Singh A., Ansari J.A., Kamakshi, and Saiyed S. S., (2014), "Investigations for Performance Improvement of X-Shaped RMSA Using Artificial Neural Network by Predicting Slot Size," Progress In Electromagnetics Research C, Vol. 47, 55-63.

[33] Mohd. A., Singh A., Ansari J.A., Kamakshi, and Saiyed S. S., (2014), " Analysis of Microstrip Line Feed Slot Loaded Patch Antenna Using Artificial Neural Network,” Progress InElectromagnetics Research B, Vol. 58, 35-46. 